\title{
Supporting Information: Designing Industrial Networks using Ecological Food Web Metrics
}

Astrid Layton

Bert Bras

Marc Weissburg

Contents: 9 pages -3 tables

Page 2 - The carpet manufacturing-recycling network (Table S1)

Page 5 - The traditional objective function (Table S2)

Page 7 - The biological objective function (Table S3) 


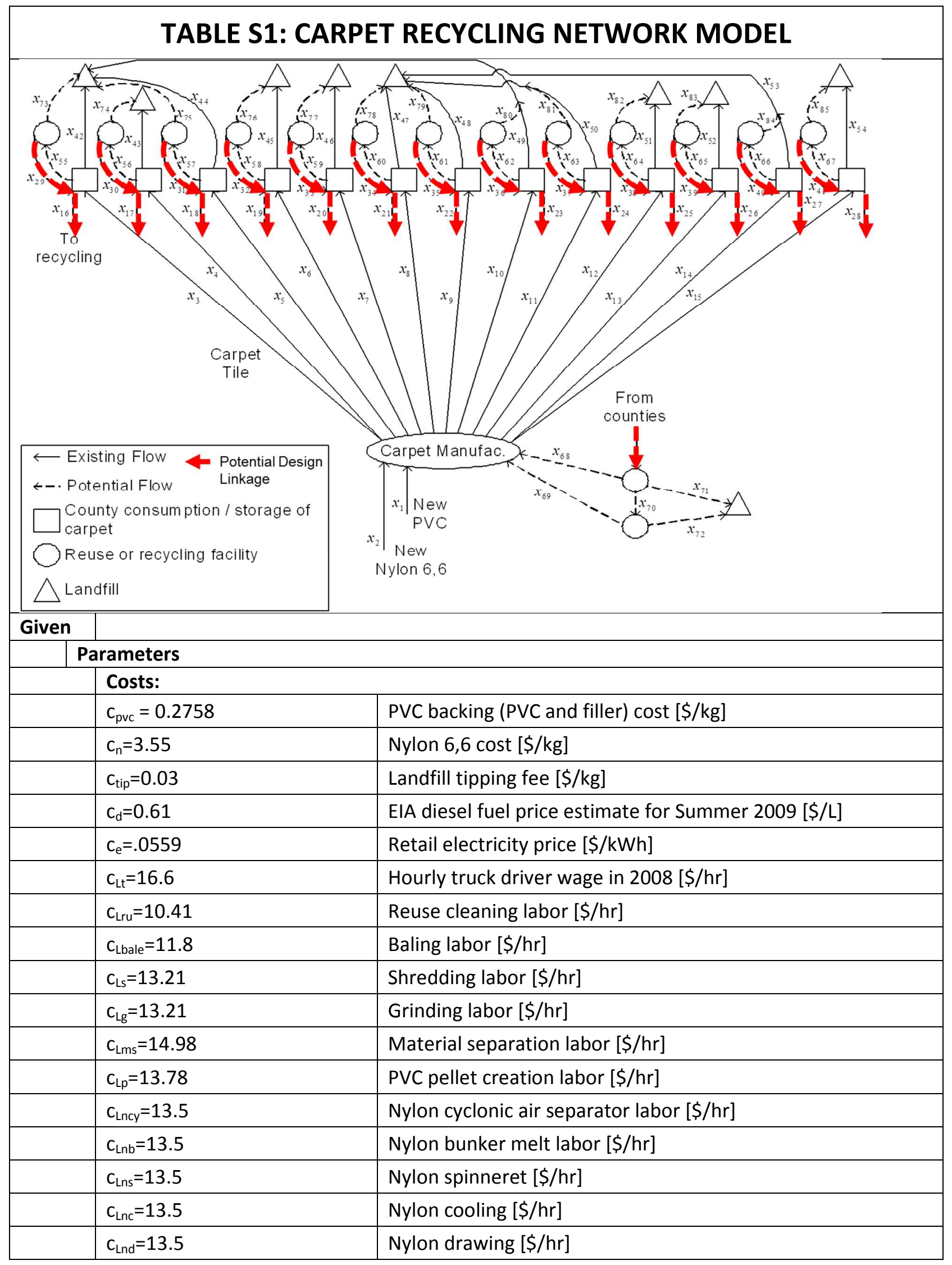




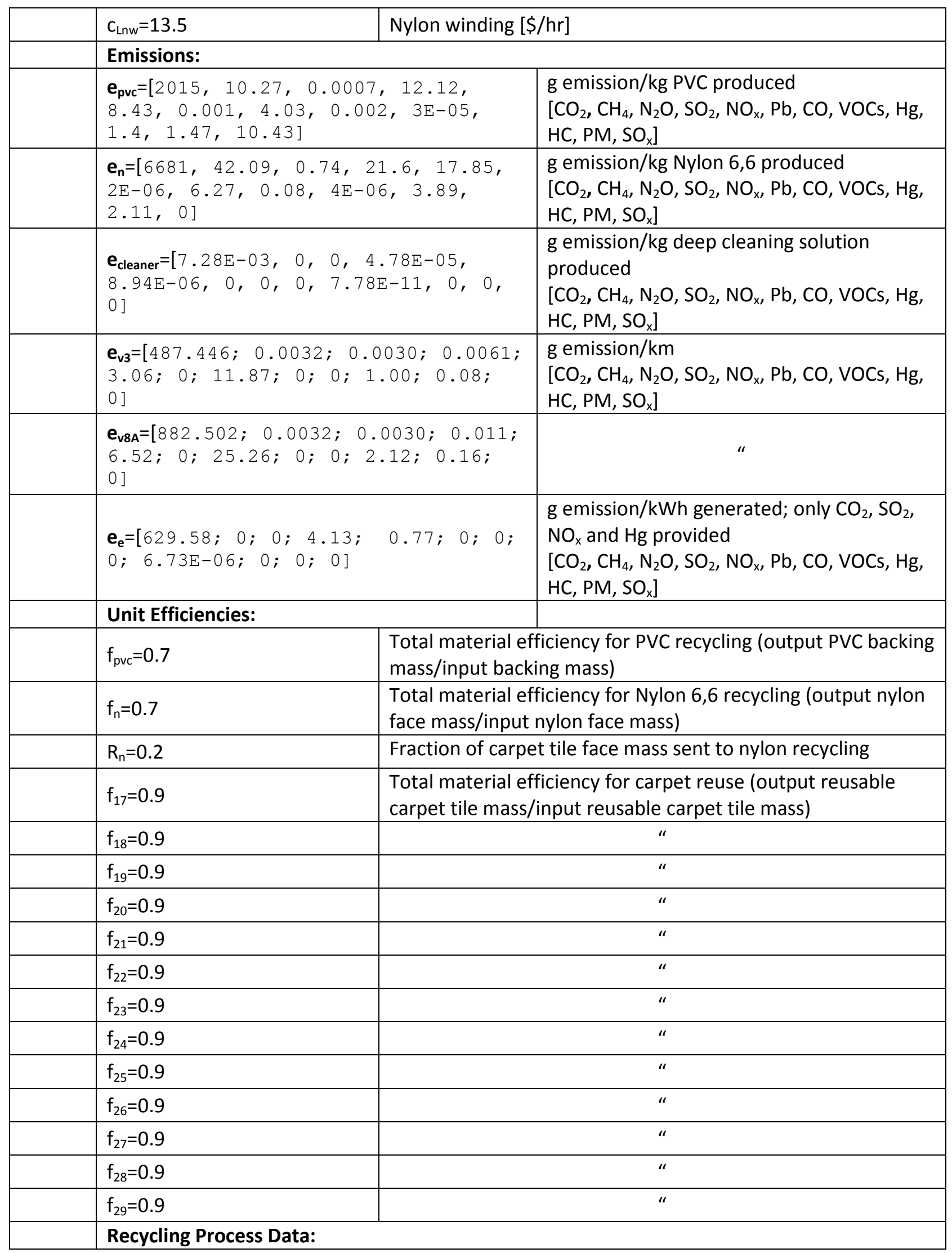




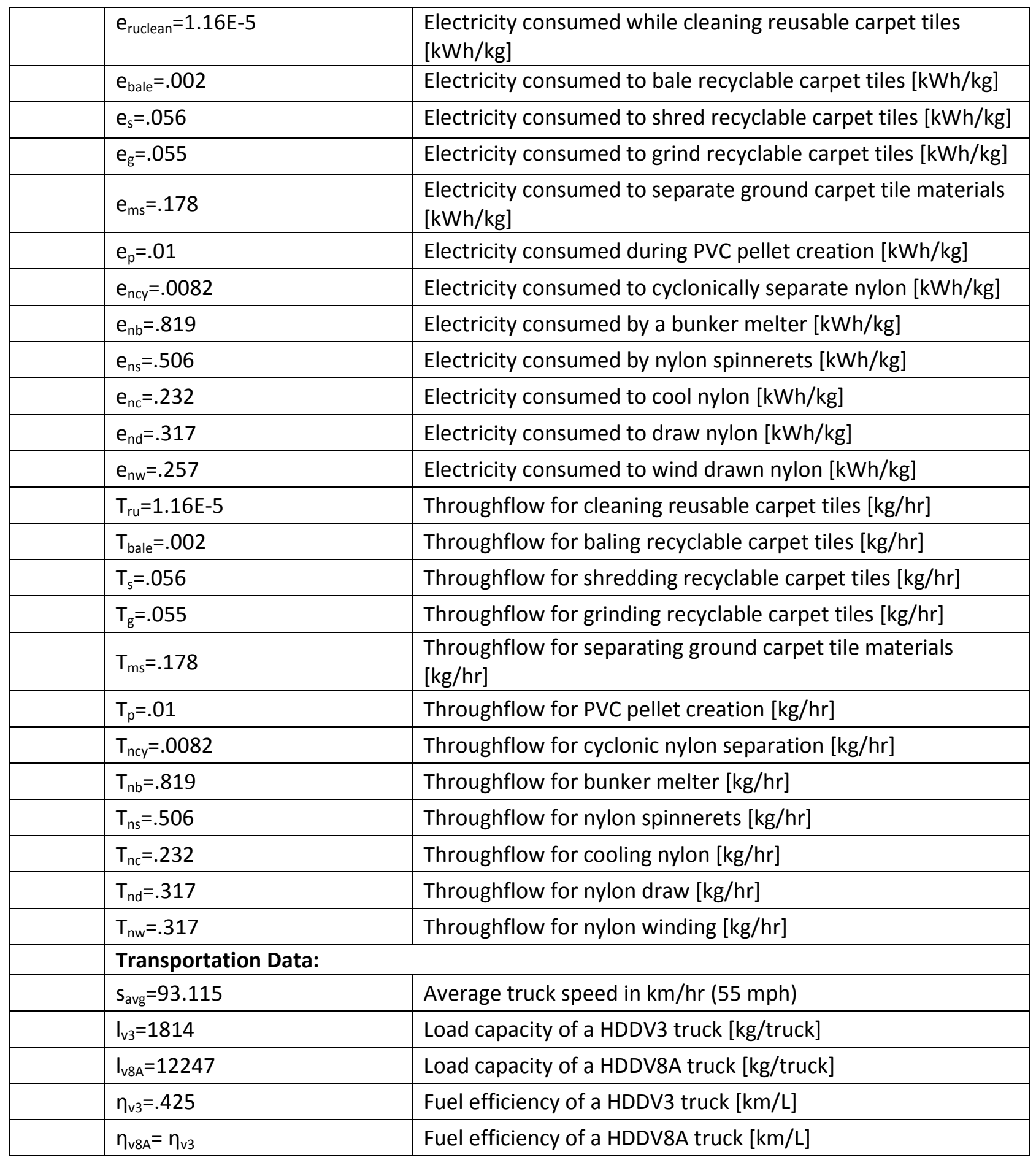

Table S1: The basic model structure for the carpet recycling network used to test the objective functions outlined in Tables S2 and S3. 


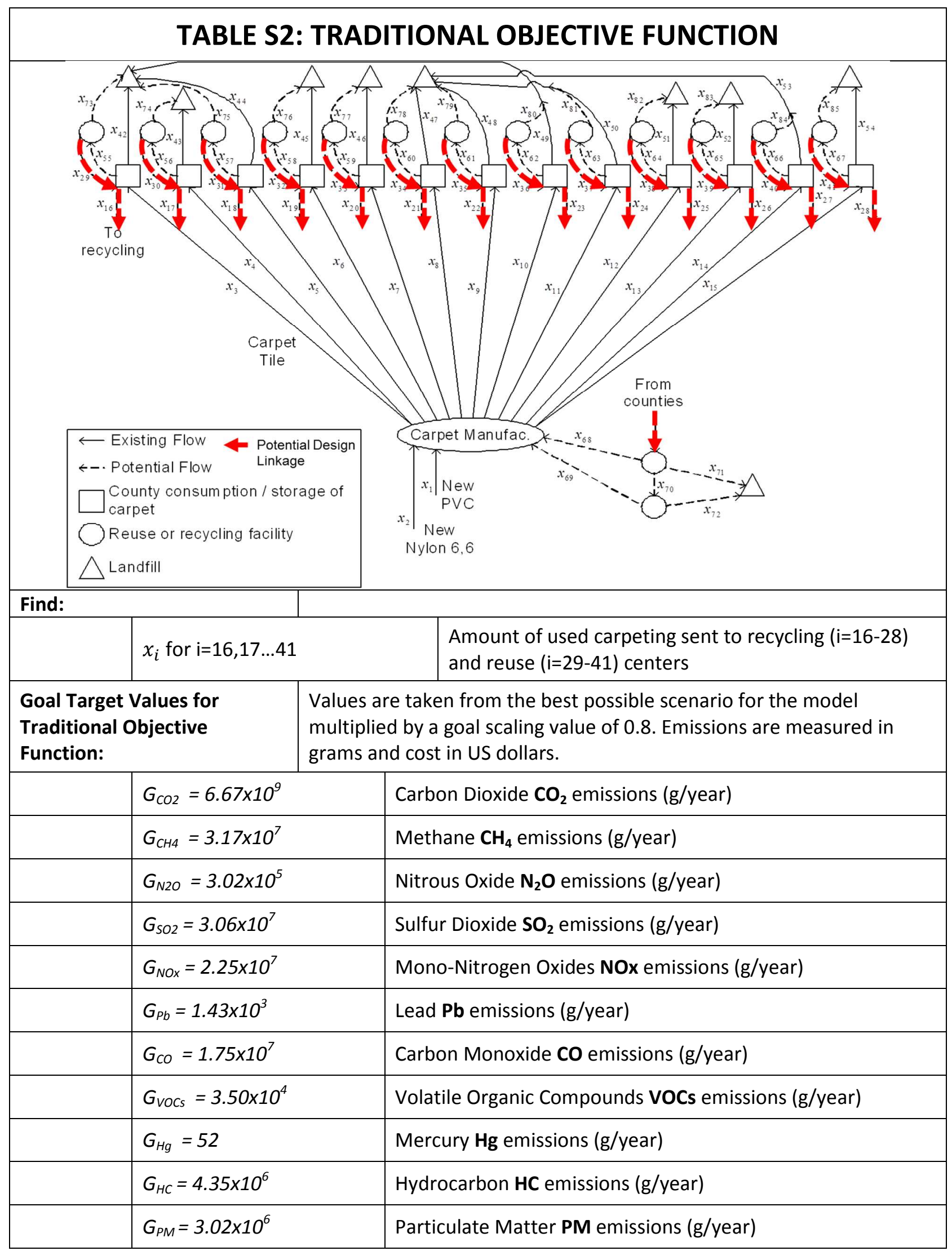




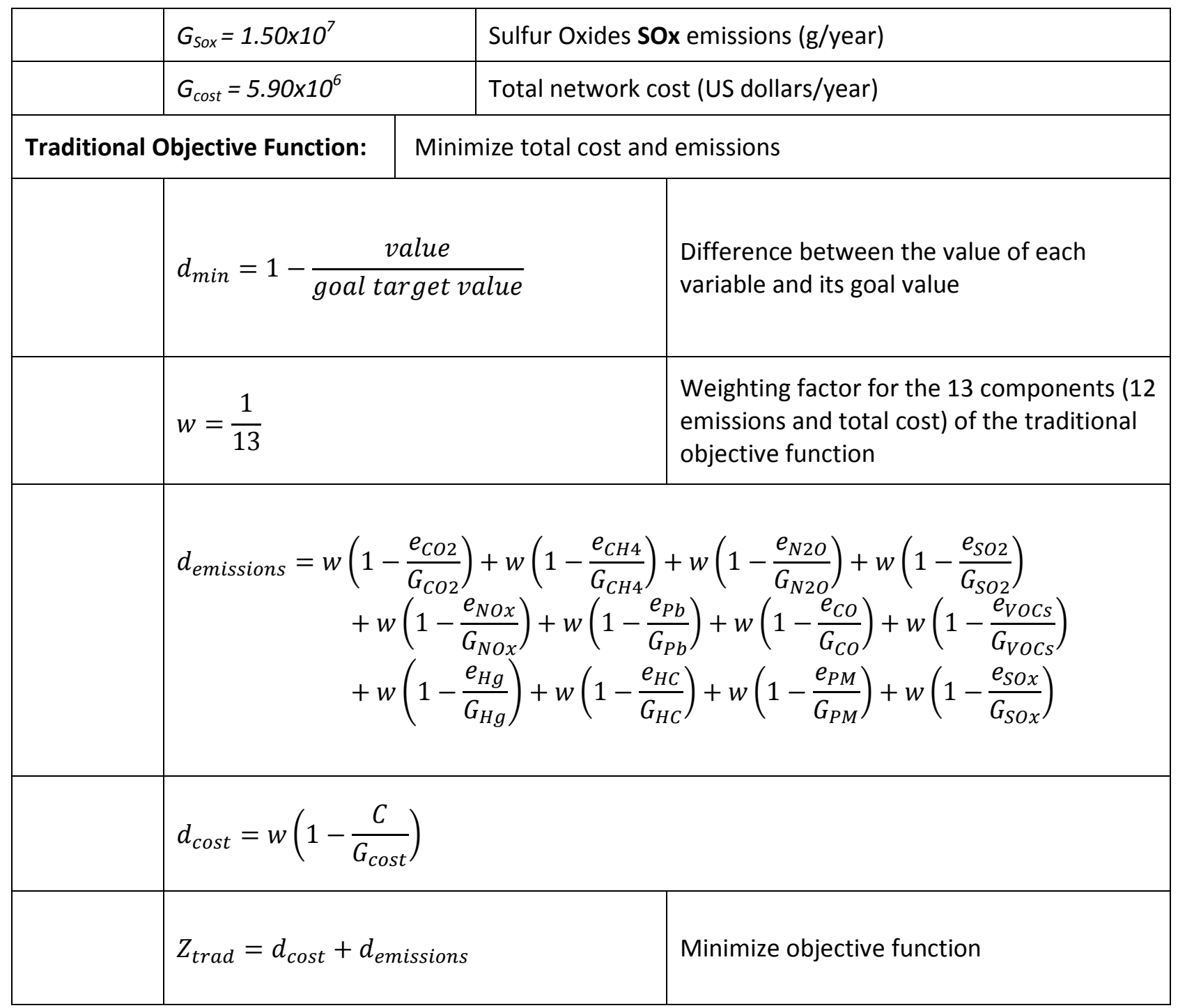

Table S2: Emission values used in calculating the traditional objective function, and the final form of the traditional objective function. 


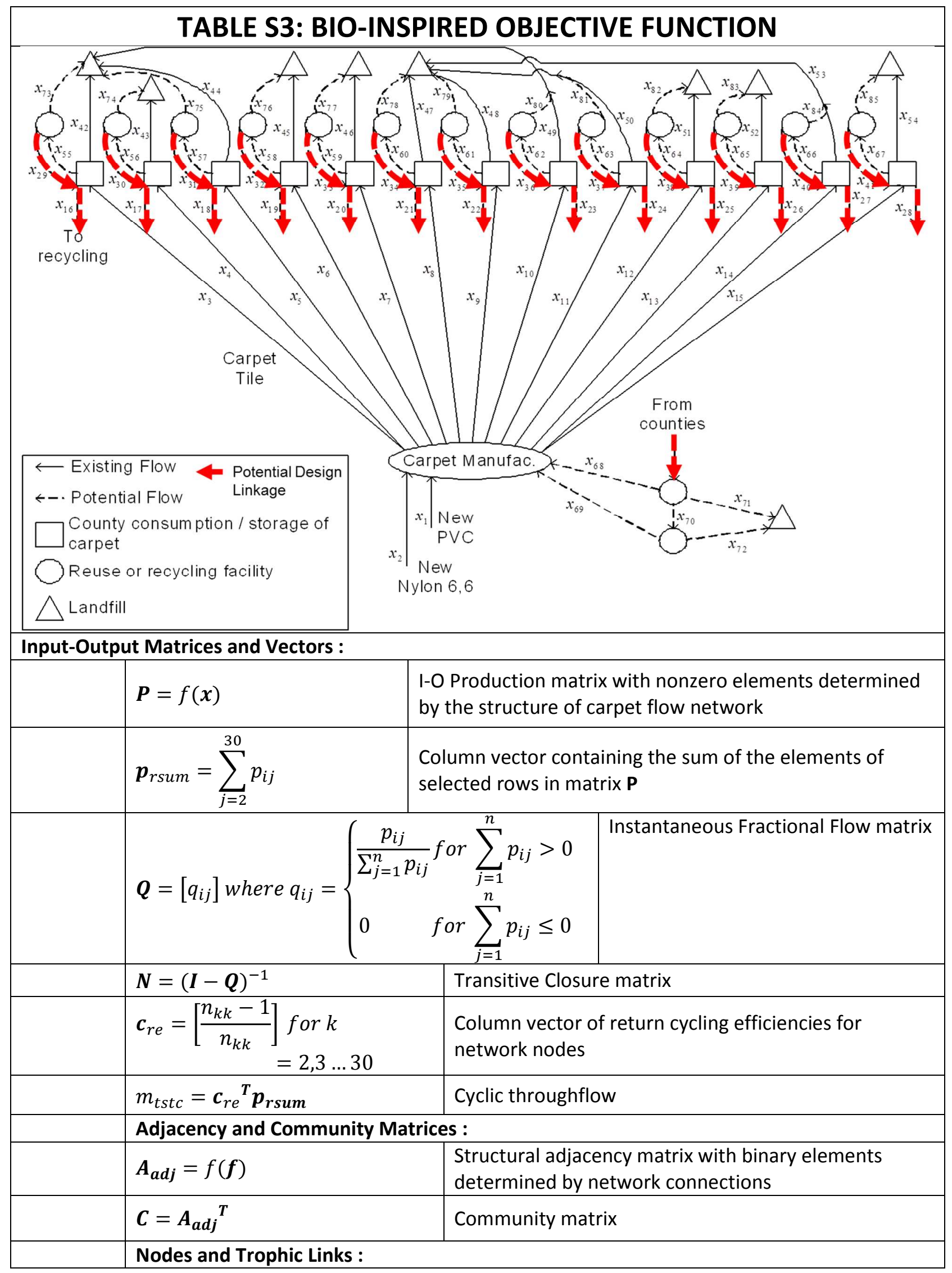




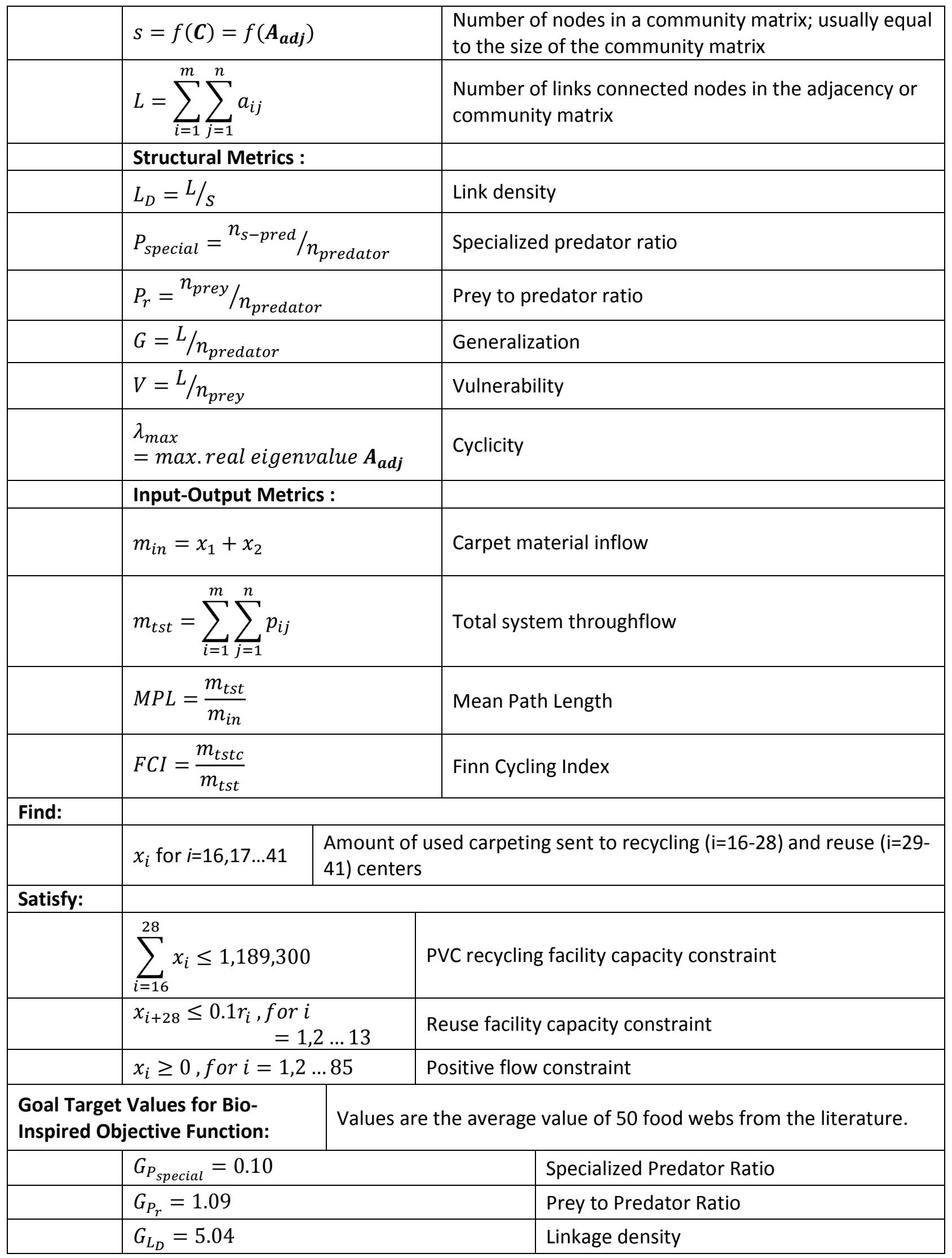




\begin{tabular}{|c|c|c|}
\hline & $G_{G}=6.18$ & Generalization \\
\hline & $G_{V}=5.34$ & Vulnerability \\
\hline & $G_{\lambda_{\max }}=4.24$ & Cyclicity \\
\hline & $G_{M P L}=5.7$ & Mean Path Length \\
\hline & $G_{F C I}=0.295$ & Finn Cycling Index \\
\hline \multicolumn{3}{|c|}{ Ainimize total difference between metrics and their goal values } \\
\hline & $1 \geq n \geq 8$ & $\begin{array}{l}n: \text { the number of metrics included in the } \\
\text { objective function }\end{array}$ \\
\hline & $w=\frac{1}{n}$ & $\begin{array}{l}\text { Weighting factor for the } 8 \text { food web metrics } \\
\text { ( } 6 \text { structural metrics and } 2 \text { flow based } \\
\text { metrics) of the bio-inspired objective } \\
\text { function }\end{array}$ \\
\hline & \multicolumn{2}{|l|}{ Minimize: } \\
\hline & $p_{\text {special }}, p_{r}$ & Metrics to reduce to reach goal values \\
\hline & $d_{\min }=1-\frac{\text { metric value }}{\text { metric goal target value }}$ & $\begin{array}{l}\text { Difference between the value of each } \\
\text { variable and its goal value }\end{array}$ \\
\hline & \multicolumn{2}{|l|}{$d_{\text {min }}=w\left(1-\frac{P_{\text {special }}}{G_{P_{\text {special }}}}\right)+w\left(1-\frac{P_{r}}{G_{P_{r}}}\right)$} \\
\hline & \multicolumn{2}{|l|}{ Maximize: } \\
\hline & $L_{D}, G, V, \lambda_{\max }, M P L, F C I$ & Metrics to increase to reach goal values \\
\hline & $d_{\max }=1-\frac{\text { metricgoal target value }}{\text { metric value }}$ & $\begin{array}{l}\text { Difference between the value of each } \\
\text { variable and its goal value }\end{array}$ \\
\hline & \multicolumn{2}{|c|}{$\begin{aligned} d_{\max }=w(1- & \left.\frac{G_{L_{D}}}{L_{D}}\right)+w\left(1-\frac{G_{G}}{G}\right)+w\left(1-\frac{G_{V}}{V}\right)+w\left(1-\frac{G_{\lambda_{\max }}}{\lambda_{\max }}\right)+w\left(1-\frac{G_{M P L}}{M P L}\right) \\
& +w\left(1-\frac{G_{F C I}}{F C I}\right)\end{aligned}$} \\
\hline & $Z_{\text {bio }}=d_{\min }+d_{\max }$ & Minimize objective function \\
\hline
\end{tabular}

Table S3: Formulas and goal values used in calculating the metrics of the bio-inspired objective function, as well as its final form. 